\title{
Correlations in the chemical composition of rural background atmospheric aerosol in the UK determined in real time using time-of-flight mass spectrometry
}

\author{
David C. S. Beddows, ${ }^{a, b}{ }_{\dagger}$ Robert J. Donovan, ${ }^{a}$ Roy M. Harrison, ${ }^{b}$ Mathew R. Heal, ${ }^{a}$ \\ Robert P. Kinnersley, ${ }^{b}$ Martin D. King, ${ }^{*}{ }^{\dagger}+$ David H. Nicholson ${ }^{a}$ and \\ Katherine C. Thompson ${ }^{a} \S$
}

\author{
${ }^{a}$ School of Chemistry, University of Edinburgh, West Mains Road, Edinburgh, UK \\ EH9 $3 J J$ \\ ${ }^{b}$ Division of Environmental Health and Risk Management, University of Birmingham, \\ Edgbaston, Birmingham, UK B15 2TT
}

Received 15th September 2003, Accepted 21st November 2003

First published as an Advance Article on the web 21st January 2004

\begin{abstract}
An aerosol time-of-flight mass spectrometer (ATOFMS) was used to determine, in real time, the size and chemical composition of individual particles in the atmosphere at the remote inland site of Eskdalemuir, Scotland. A total of 51980 particles, in the size range 0.3-7.4 $\mu \mathrm{m}$, were detected between the 25 th and 30 th June 2001. Rapid changes in the number density, size and chemical composition of the atmospheric aerosol were observed. These changes are attributed to two distinct types of air mass; a polluted air mass that had passed over the British mainland before reaching Eskdalemuir, interposed between two cleaner air masses that had arrived directly from the sea. Such changes in the background aerosol could clearly be very important to studies of urban aerosols and attempts at source apportionment. The results of an objective method of data analysis are presented. Correlations were sought between the occurrence of: lithium, potassium, rubidium, caesium, beryllium, strontium, barium, ammonium, amines, nitrate, nitrite, boron, mercury, sulfate, phosphate, fluorine, chlorine, bromine, iodine and carbon (both elemental and organic hydrocarbon) in both fine $(d<$ $2.5 \mu \mathrm{m})$ and coarse $(d>2.5 \mu \mathrm{m})$ particle fractions. Several previously unreported correlations were observed, for instance between the elements lithium, beryllium and boron. The results suggest that about 2 in 3 of all fine particles (by number rather than by mass), and 1 in 2 of all coarse particles containing carbon, consisted of elemental carbon rather than organic hydrocarbon (although a bias in the sensitivity of the ATOFMS could have affected these numbers). The ratio of the number of coarse particles containing nitrate anions to the number of particles containing chloride anions exceeded unity when the air mass had travelled over the British mainland. The analysis also illustrates that an air mass of marine origin that had travelled slowly over agricultural land can accumulate amines and ammonium.
\end{abstract}

\section{Introduction}

A detailed knowledge of the chemical composition of particles present in the atmosphere, alongside a knowledge of their size and concentration, is crucial to determining the sources of particulate matter in the atmosphere, assessing the health problems associated with airborne particles, and to understanding the influence of particles on atmospheric chemistry and vice versa. The atmospheric particle burden is extremely diverse and influenced by a multitude of sources and transformation processes. While much progress has been made in understanding and quantifying the atmospheric particulate system, ${ }^{1}$ more needs to be resolved. Much of the uncertainty stems from a lack of measurement techniques with sufficient time resolution. Traditional chemical speciation is dependent on accumulation of sufficient material (often over days) on traps or filters and subsequent off-line analyses. These

\footnotetext{
$\uparrow$ Present address: Department of Physics, University of Wales Swansea, Singleton Park, Swansea, SA2 8PP, UK.

$\downarrow$ Present address: Department of Geology, Royal Holloway University of London, Egham, Surrey, TW20 0EX, UK. E-mail: m.king@ gl.rhul.ac.uk; Fax: +44 (0)1784 471780; Tel: +44 (0)1784 414038 .

$\S$ Present address: School of Biological and Chemical Sciences, Birkbeck College, University of London, Malet Street, Bloomsbury, London, WC1E 7HX, UK.
}

methods do not allow the chemical composition of individual particles to be ascertained.

Over the past few years there has been considerable development of instrumentation capable of sizing and chemically characterising airborne particles in real time. ${ }^{2-9}$ The considerably enhanced time resolution provided by these instruments permits investigation of correlations in chemical composition of particles, and of the role of meteorology and chemistry in the evolution of the particle burden in the atmosphere.

In this work we describe the deployment of an aerosol timeof-flight mass spectrometer (ATOFMS) ${ }^{2}$ to study the rural background aerosol. In contrast to some other single-particle instrumentation, the ATOFMS yields, simultaneously, size and chemical composition data for each particle analysed, together with information on changes in number density with time. The ATOFMS was sited at Eskdalemuir $\left(55.3^{\circ} \mathrm{N}, 3.2^{\circ} \mathrm{W}\right.$; elevation, $250 \mathrm{~m}$ ), a remote location in the Southern Uplands of Scotland approximately $80 \mathrm{~km}$ south of Edinburgh and $100 \mathrm{~km}$ south east of Glasgow. The site is surrounded by animal pasture, unimproved moorland and coniferous forest plantations. Sampling was undertaken continuously between 20:00 on 25th June and 09:00 on 30th June 2001 (Julian Days 176 to 181). This study is a prelude to a series of studies on urban aerosols which will be reported in due course.

During the campaign the mass spectra of 51980 individual particles were recorded. The emphasis in this study was on the 
elemental composition of the aerosol particles and the data were analysed in a manner that assumed no prior knowledge or preconceived idea as to the origin or chemical nature of the particles. The method of analysis does not group the particles into broad categories such as sea salt, nitrate, elemental carbon etc.; rather, correlations were determined between a suite of species (both elemental and molecular) present in individual size-fractionated particles. The correlations were related to changes in air mass source region during sampling. The enormous versatility of the ATOFMS instrument in elucidating the composition of particles in the atmosphere is demonstrated.

\section{Experimental}

\subsection{Description of the ATOFMS}

The main features of the aerosol time-of-flight mass spectrometer (ATOFMS) instrument used here (TSI, Model 3800) have been described previously, ${ }^{2}$ and only an overview is presented here. Air is sampled from the atmosphere through a differentially pumped aerodynamic nozzle to produce a collimated beam containing the particles which then passes two orthogonal laser beams (532 nm, diode-pumped solid state lasers) separated by a known distance. Scattered light from a particle actuates a timing circuit and the transit time yields the aerodynamic diameter of the particle. The particles pass through to a mass spectrometer section where material is ablated and ionised in the focus of a pulsed UV laser light at $266 \mathrm{~nm}$ (frequency quadrupled Nd-YAG laser). The desorption-ionisation laser is triggered by the same timing circuit used to size the particles. The mass-to-charge ratios of both the positive and the negative ions produced are determined simultaneously in two time-of-flight reflectron mass spectrometers. Only the 400 ions giving rise to the largest signal were considered in the analysis of each spectrum, with the limitation that the smallest signal to noise ratio used was $\sim 2: 1$.

Although, in principle, particles with aerodynamic diameter $0.3 \mu \mathrm{m}$ to $10 \mu \mathrm{m}$ can be detected and sized, size-sampling efficiency is not uniform. For a similar ATOFMS instrument, Allen et al. ${ }^{10}$ showed that particle detection efficiency obeyed a power law on diameter in the range $0.32-1.8 \mu \mathrm{m}$, decreasing by two orders of magnitude over this range. Since sizing efficiency must be determined for each instrument individually and, since for this work, only a division between fine and coarse particles was required, no attempt was made to "correct" for sizing efficiency. The minimum and maximum particle diameters detected in this work were 0.36 and $7.4 \mu \mathrm{m}$, respectively.

The ablation and ionisation process used in this work has been studied by a number of groups. ${ }^{11}$ A limitation of the timeof-flight mass spectrometer is its inability to yield direct quantitative information on the amount of each chemical species in each particle. However, the work presented sought only to correlate chemical species present in rural aerosol, not to quantify the amounts. There are relatively few published attempts to quantify the response of ATOFMS instruments to particles of known composition. Bhave et al. ${ }^{12}$ demonstrated that the detection efficiency of their ATOFMS to $\mathrm{NH}_{4}{ }^{+}$and $\mathrm{NO}_{3}{ }^{-}$was reduced as the particle diameter decreased from 1.8 to $0.32 \mu \mathrm{m}$, as compared with collocated impactor measurements. Gross et al. ${ }^{13}$ determined relative sensitivity factors of $0.14,5.1,6.0,7.9$ and 0.014 for detection of the ions $\mathrm{Li}^{+}, \mathrm{K}^{+}$, $\mathrm{Rb}^{+}, \mathrm{Cs}^{+}$and $\mathrm{NH}_{4}^{+}$, respectively, relative to $\mathrm{Na}^{+}$. The trend of increased detection efficiency with atomic number for these ions correlated with lattice energies and ionisation potentials for the precursor salts and elements respectively. The authors tested the machine in the laboratory before committing it to the field. Using artificial aerosol generated in the laboratory we investigated the typical response of expected chemical constituents of common aerosols in the laboratory.

\subsection{Mass calibration}

A reliable method of mass calibration for the time-of-flight signal was the obvious series of peaks separated by $12 \mathrm{Da}$ provided when elemental carbon particles were detected. Mass calibration was undertaken every hour throughout the field campaign by sampling particles produced from nebulisation of a calibration solution containing an aqueous solution of the ions $\mathrm{Na}^{+}, \mathrm{Fe}^{3+}$, $\mathrm{Zn}^{2+}, \mathrm{Pb}^{2+}, \mathrm{Cl}^{-}, \mathrm{SO}_{4}{ }^{2-}$, and $\mathrm{NO}_{3}{ }^{-}$. It should be noted that when identifying ions from their mass spectra it is possible that other species present may have the same mass and thus cause interference. All likely interferences of this kind were considered and the conclusions presented in the text for each relevant species. However, the possibility of interference caused by the presence of an unsuspected species cannot be completely ruled out.

\subsection{Aerosol sampling and meteorological data}

The ATOFMS was housed in a static van throughout the campaign. Outside air was sampled into the inlet of the instrument from approximately $2 \mathrm{~m}$ height above the ground through a $2 \mathrm{~m}$ length of $2.5 \mathrm{~cm}$ (OD) clean copper tubing. A portable meteorological station (Campbell) was positioned within $50 \mathrm{~m}$ of the vehicle and recorded wind speed and direction, relative humidity (at $1.4 \mathrm{~m}$ height), air temperature and visible irradiance as $5 \mathrm{~min}$ averages.

\subsection{Air mass back trajectories}

Back trajectories were calculated for 00:00, 06:00, 12:00 and 18:00 h on Julian days (JD) 176.5-181.5 of the campaign using the models available from the British Atmospheric Data Centre. Parcel pressures of 900, 950 and 1000 mbar and potential temperatures of 300,320 and $340 \mathrm{~K}$ were used for vertical advection and isentropic models, respectively. Both models gave similar results. Clusters of trajectories arriving at a $10 \mathrm{~km}$ radius of the field site were also similar, indicating that the air mass source regions were well-characterised.

\section{Results and discussion}

\subsection{Air mass source region and local meteorology}

The back trajectories, which were obtained after the field campaign, revealed a major switch in air mass source region during sampling. From JD 176.5 to JD 177.5, and again from JD 179.0 to JD 181.5 , air masses followed an almost entirely marine path over the Atlantic Ocean and Irish Sea before reaching Eskdalemuir. In contrast, back trajectories in the period JD 177.5 to JD 178.75 travelled over mainland Britain from a southerly direction. Examples of these "clean/marine" and "dirty/continental" air masses are illustrated in Fig. 1.

During the campaign, local winds remained light $\left(<1-6 \mathrm{~m} \mathrm{~s}^{-1}\right)$, relative humidity was high $(80-\sim 100 \%)$, and there was little diurnal temperature variation $\left(11-16{ }^{\circ} \mathrm{C}\right.$ ). A large (for the United Kingdom) thunderstorm impacted the site between JD 177.75 and 178.0 and was the only precipitation event. The local meteorological variables did not correlate with the size or chemical composition of the particles. This confirms the absence of a local point source of particles, which is not surprising given the remoteness of the sampling site.

\subsection{Variation of particle size fractions}

The size, and positive and negative ion mass spectra of all 51980 particles recorded during the campaign were grouped into $1 \mathrm{~h}$ time intervals. Although the ATOFMS provided a quasicontinuum of size classification, particles were re-classified as either fine $(<2.5 \mu \mathrm{m})$ or coarse $(>2.5 \mu \mathrm{m})$ in order to expedite analysis of this large dataset. This yielded 30949 fine and 21031 coarse particles. The maximum number of fine and coarse particles detected were $1379 \mathrm{~h}^{-1}$, at around 06:00 on day 178, and 

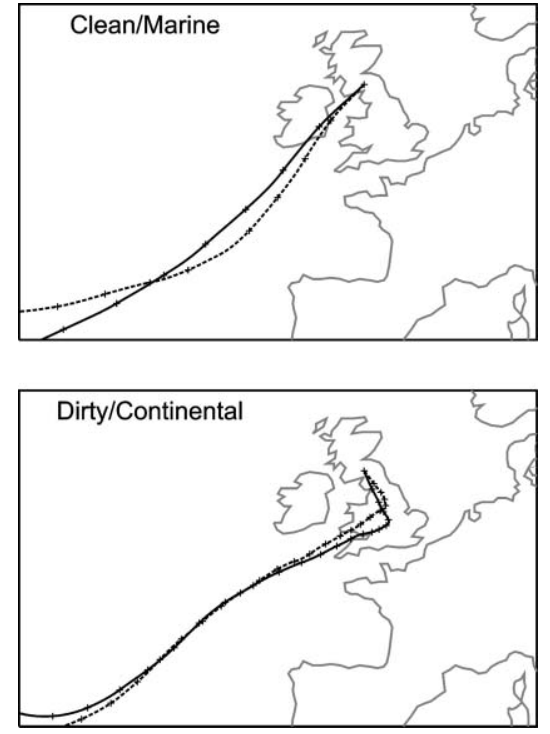

Fig. 1 Back trajectories illustrating the two types of air mass experienced during the measurement campaign. Solid and dashed lines are trajectories arriving at 900 and 950 mbar, respectively. Markers are at $6 \mathrm{~h}$ intervals. The upper pane is for JD 180.5 and shows $\sim 2$ days of an example "clean/marine" air mass trajectory. The lower pane is for JD 177.5 and shows $\sim 6$ days of an example "dirty" air mass trajectory.

$1126 \mathrm{~h}^{-1}$, at around 20:00 on day 178 , respectively. The time series of hourly particle numbers is shown in Fig. 2. The elevated total number of particles in the air mass that passed over the mainland UK is striking, as is the significant increase in the ratio of fine particles relative to coarse particles in this dirty air mass.

\subsection{Correlations between particle chemical composition}

Each time-of-flight mass spectrum was converted into a conventional stick mass spectrum using calibration values described in Section 2.2. The stick mass spectra, and the associated size data for the particles, were placed in Microsoft Access databases from which it was possible to query the number of occurrences of a species of $x$ Da in each hourly period. Tables 1 and 2 summarise

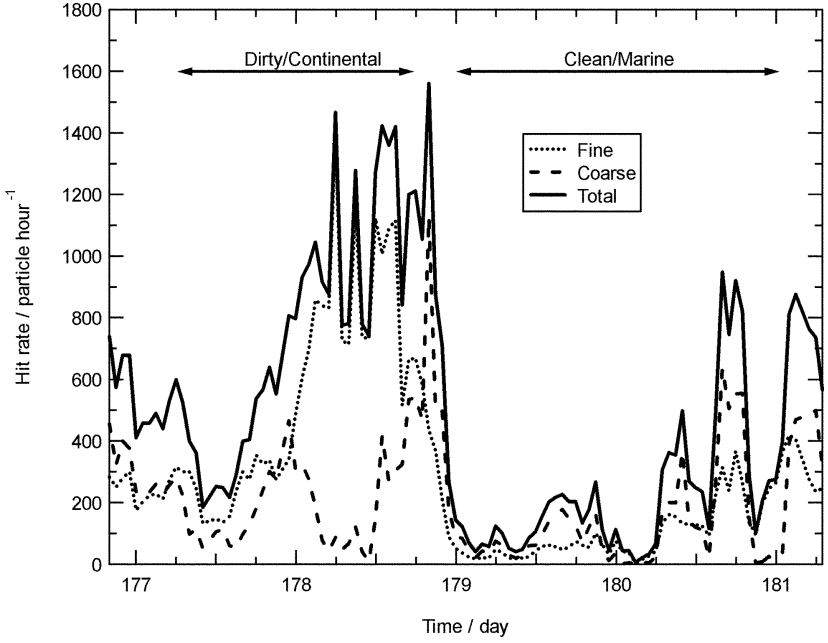

Fig. 2 The number of coarse and fine particles detected per hour. The periods corresponding to "dirty" or "clean" air mass were determined by 6 hourly back trajectories.

the percentage of the total number of coarse and fine particles that contained each chemical species considered, and the maximum number of occurrences of particles containing the species that were detected in any one hour period.

Tables 3 and 4 list, for fine and coarse particles respectively, the correlation matrices (crosses indicate $r^{2}>0.5$ ) for the hourly number of occurrences of pairs of species of $x$ and $y \mathrm{Da}$, for those species examined. It should be noted that the chemical analyses performed were not mutually exclusive: a particle found to contain potassium and sodium would not be classified as solely sodium or solely potassium, but classified as containing sodium and classified as containing potassium.

The databases could also be interrogated using basic logic commands. For example, searching for $\mathrm{m} / \mathrm{z}=200$ AND 202 $\mathrm{Da}$ (i.e. both common isotopes) yielded more confidence for the presence of mercury in a particle.

3.3.1 Positive ions. Lithium. The ATOFMS is particularly useful for detecting lithium since the X-ray techniques often used to

Table 1 A summary of species detected in the positive ion time-of-flight mass spectra of single particles at Eskdalemuir, June 2001

\begin{tabular}{|c|c|c|c|c|}
\hline Element or ion: Daltons & Fine $^{a}$ & Coarse $^{a}$ & Maximum number, fine ${ }^{b}$ & Maximum number, coarse $\mathrm{e}^{b}$ \\
\hline Lithium: 7 & $2.0 \%$ & $2.7 \%$ & $22(12.8 \%, 178.12)$ & $26(6.3 \%, 178.54)$ \\
\hline Sodium: 23 & $50.1 \%$ & $96.4 \%$ & $456(68.2 \%, 178.75)$ & $1111(98.7 \%, 178.83)$ \\
\hline Potassium: 39 AND 41 & $44.3 \%$ & $87.4 \%$ & $412(61.7 \%, 178.75)$ & $1039(92.3 \%, 178.83)$ \\
\hline Rubidium: 85 AND 87 NOT 86 & $3.0 \%$ & $1.9 \%$ & $32(10.5 \%, 177.29)$ & $16(3.9 \%, 178.54)$ \\
\hline Caesium: 133 & $3.2 \%$ & $2.2 \%$ & $40(2.9 \%, 178.25)$ & $24(5.8 \%, 178.54)$ \\
\hline Caesium: 133 NOT 132 & $1.1 \%$ & $1.2 \%$ & $16(1.2 \%, 178.25)$ & $10(2.7 \%, 176.92)$ \\
\hline Beryllium: 9 & $0.4 \%$ & $0.8 \%$ & $7(3.4 \%, 177.12)$ & $9(7.3 \%, 177.71)$ \\
\hline Strontium: 88 & $2.4 \%$ & $3.8 \%$ & $28(8.8 \%, 177.25)$ & $32(7.1 \%, 176.83)$ \\
\hline Barium: 138 & $1.6 \%$ & $1.9 \%$ & $18(6.3 \%, 177.29)$ & $20(3.7 \%, 178.70)$ \\
\hline Mercury: 200 & $0.7 \%$ & $0.6 \%$ & $10(1.2 \%, 178.12)$ & $8(1.7 \%, 178.00)$ \\
\hline Mercury: 200 AND 202 & $0.4 \%$ & $0.2 \%$ & $7(3.9 \%, 177.50)$ & $4(4.1 \%, 177.33)$ \\
\hline Boron: 11 & $0.4 \%$ & $0.5 \%$ & $7(2.5 \%, 177.71)$ & $5(3.9 \%, 177.71)$ \\
\hline $\mathrm{C}: 12$ & $58.2 \%$ & $12.3 \%$ & $1208(87.6 \%, 178.25)$ & $155(37.3 \%, 178.54)$ \\
\hline $\mathrm{C}_{3}: 36$ & $65.1 \%$ & $18.2 \%$ & $1284(93.1 \%, 178.25)$ & $237(57.1 \%, 178.54)$ \\
\hline $\mathrm{C}, \mathrm{C}_{3}, \mathrm{C}_{7}: 12,36,84$ & $10.7 \%$ & $3.2 \%$ & $223(16.2 \%, 178.25)$ & $51(12.3 \%, 178.54)$ \\
\hline C, $\mathrm{CH}, \mathrm{CH}_{2}: 12,13,14$ & $0.5 \%$ & $0.2 \%$ & $19(38.2 \%, 179.75)$ & $7(7.6 \%, 179.00)$ \\
\hline $\mathrm{C}_{3}, \mathrm{C}_{3} \mathrm{H}, \mathrm{C}_{3} \mathrm{H}_{2}: 36,37,38$ & $23.6 \%$ & $7.0 \%$ & $454(32.9 \%, 178.25)$ & $106(19.8 \%, 178.70)$ \\
\hline $\mathrm{NH}_{4} \mathrm{NO}_{3}: 80$ & $3.5 \%$ & $9.3 \%$ & $41(6.1 \%, 178.75)$ & $72(6.4 \%, 178.83)$ \\
\hline $\mathrm{NH}_{4}\left(\right.$ or $\left.\mathrm{H}_{2} \mathrm{O}\right): 18$ & $20.6 \%$ & $9.7 \%$ & $419(30.4 \%, 178.25)$ & $109(35.9 \%, 178.62)$ \\
\hline $\mathrm{NH}_{3} \cdot \mathrm{NH}_{4}: 35$ & $22.7 \%$ & $4.5 \%$ & $463(40.1 \% .178 .37)$ & $70(16.9 \%, 178.54)$ \\
\hline $\mathrm{CH}_{4} \mathrm{~N}\left(\right.$ or $\left.\mathrm{NO}^{+}\right): 30$ & $20.8 \%$ & $30.0 \%$ & $362(26.3 \%, 178.25)$ & $300(26.6 \%, 178.83)$ \\
\hline $\mathrm{C}_{3} \mathrm{H}_{8} \mathrm{~N}: 58$ & $12.7 \%$ & $19.5 \%$ & $202(17.5 \%, 178.37)$ & $170(15.1 \%, 178.83)$ \\
\hline $\mathrm{C}_{5} \mathrm{H}_{12} \mathrm{~N}: 86$ & $7.5 \%$ & $5.4 \%$ & $105(14.3 \%, 178.45)$ & $44(10.6 \%, 178.54)$ \\
\hline Amines: 30 AND 58 AND 86 & $2.7 \%$ & $2.3 \%$ & $39(12.3 \%, 177.25)$ & $22(4.7 \%, 177.95)$ \\
\hline
\end{tabular}

${ }^{a}$ Percentage of all fine $(<2.5 \mu \mathrm{m})$ or all coarse $(d>2.5 \mu \mathrm{m})$ particles which contain the species. ${ }^{b}$ The maximum number of fine or coarse particles which contain the species in any one hour period. The numbers in parentheses are the percentage of particles in that hour period that contained the species, and the Julian day fraction at which this hour period occurred. 
Table 2 A summary of species detected in the negative ion time-of-flight mass spectra of single particles at Eskdalemuir, June 2001

\begin{tabular}{|c|c|c|c|c|}
\hline Element or ion: Daltons & Fine $^{a}$ & Coarse $^{a}$ & Maximum number, fine ${ }^{b}$ & Maximum number, coarse ${ }^{b}$ \\
\hline Fluorine: 19 & $0.3 \%$ & $0.3 \%$ & $7(2.6 \%, 177.21)$ & $4(1.1 \%, 176.96)$ \\
\hline Chlorine: 35 & $6.1 \%$ & $20.4 \%$ & $80(19.7 \%, 181.12)$ & $351(20.4 \%, 176.83)$ \\
\hline Bromine: 79 AND 81 & $4.5 \%$ & $6.6 \%$ & $79(28.8 \%, 177.17)$ & $97(34.3 \%, 177.25)$ \\
\hline Iodine: 127 & $0.7 \%$ & $1.2 \%$ & $15(1.4 \%, 178.58)$ & $18(6.9 \%, 177.12)$ \\
\hline $\mathrm{NO}_{2}{ }^{-}: 46$ & $15.9 \%$ & $38.3 \%$ & $182(16.3 \%, 178.62)$ & $401(87.9 \%, 176.83)$ \\
\hline $\mathrm{NO}_{3}^{-}: 62$ & $17.7 \%$ & $35.7 \%$ & $259(23.2 \%, 178.62)$ & $387(84.9 \%, 176.83)$ \\
\hline $\mathrm{NO}_{3}{ }^{-}: 62$ NOT 60 & $13.2 \%$ & $29.5 \%$ & $222(19.9 \%, 178.62)$ & $315(58.9 \%, 178.70)$ \\
\hline $\mathrm{SO}_{3}{ }^{-}: 80$ & $7.5 \%$ & $10.7 \%$ & $96(8.8 \%, 178.58)$ & $157(34.4 \%, 176.83)$ \\
\hline $\mathrm{HSO}_{3}{ }^{-}: 81$ & $4.7 \%$ & $3.1 \%$ & $78(5.7 \%, 178.25)$ & $46(17.6 \%, 177.12)$ \\
\hline $\mathrm{HSO}_{3}{ }^{-}: 81$ NOT 79 & $2.9 \%$ & $1.1 \%$ & $73(6.3 \%, 178.37)$ & $20(16.4 \%, 178.37)$ \\
\hline $\mathrm{SO}_{4}^{-2}: 96$ & $10.6 \%$ & $11.8 \%$ & $121(49.0 \%, 177.38)$ & $220(48.2 \%, 176.83)$ \\
\hline $\mathrm{SO}_{4}^{-}: 96$ NOT 84 & $8.8 \%$ & $9.2 \%$ & $102(32.3 \%, 177.25)$ & $205(45.0 \%, 176.83)$ \\
\hline $\mathrm{HSO}_{4}^{-}: 97$ & $13.3 \%$ & $9.2 \%$ & $239(20.7 \%, 178.37)$ & $132(28.9 \%, 176.83)$ \\
\hline $\mathrm{PO}_{2}^{-}: 63$ & $6.4 \%$ & $9.5 \%$ & $150(10.9 \%, 178.25)$ & $116(41.0 \%, 177.25)$ \\
\hline $\mathrm{PO}_{4}^{-}: 95$ & $5.1 \%$ & $9.7 \%$ & $68(27.5 \%, 177.38)$ & $229(50.2 \%, 176.83)$ \\
\hline $\mathrm{O}^{-}: 16$ & $13.9 \%$ & $24.6 \%$ & $259(82.0 \%, 177.25)$ & $421(92.3 \%, 176.83)$ \\
\hline $\mathrm{OH}^{-}: 17$ & $8.8 \%$ & $20.5 \%$ & $121(42.6 \%, 176.83)$ & $390(85.5 \%, 176.83)$ \\
\hline
\end{tabular}

${ }^{a}$ Percentage of all fine $(<2.5 \mu \mathrm{m})$ or all coarse $(d>2.5 \mu \mathrm{m})$ particles which contain the species. ${ }^{b}$ The maximum number of fine or coarse particles which contain the species in any one hour period. The numbers in parentheses are the percentage of particles in that hour period that contained the species, and the Julian day fraction at which this hour period occurred.

detect metals in bulk particle samples are not sensitive to lithium. ${ }^{4}$ During this campaign, $2.0 \%$ and $2.7 \%$, respectively, of fine and coarse particles contained lithium $(\mathrm{m} / \mathrm{z}=7 \mathrm{Da})$. The temporal behaviour of coarse and fine particulate lithium was similar. Lithium occurs naturally in crustal rocks (18 ppm by mass globally) and has been detected by ATOFMS in Californian soil dust. ${ }^{14}$ In a measurement campaign with a single particle mass spectrometer at Idaho Hill in the US, 9\% of particles analysed were found to contain lithium, and these particles correlated positively with those containing potassium and sodium. ${ }^{4}$ No such correlation was observed in this study (Tables 3 and 4). However, fine particle lithium was correlated with fine particle barium which is probably indicative of an automotive source, since barium is associated with automobile emissions. ${ }^{13}$ One anthropogenic source of $\mathrm{Li}$ includes high temperature automobile greases, alongside fluxes for porcelain enamels and aluminium brazing. ${ }^{16}$

Sodium. Sodium, and other alkali metals, are readily detected by the ATOFMS because of the low ionisation energies. It was found that nearly all coarse particles and half of all fine particles contained sodium $(\mathrm{m} / \mathrm{z}=23 \mathrm{Da})$. This reflects the prevailing maritime meteorology at Eskdalemuir, with seasalt contributing particularly to the coarse mode. The temporal trend, shown in Fig. 3, in numbers of fine particles containing

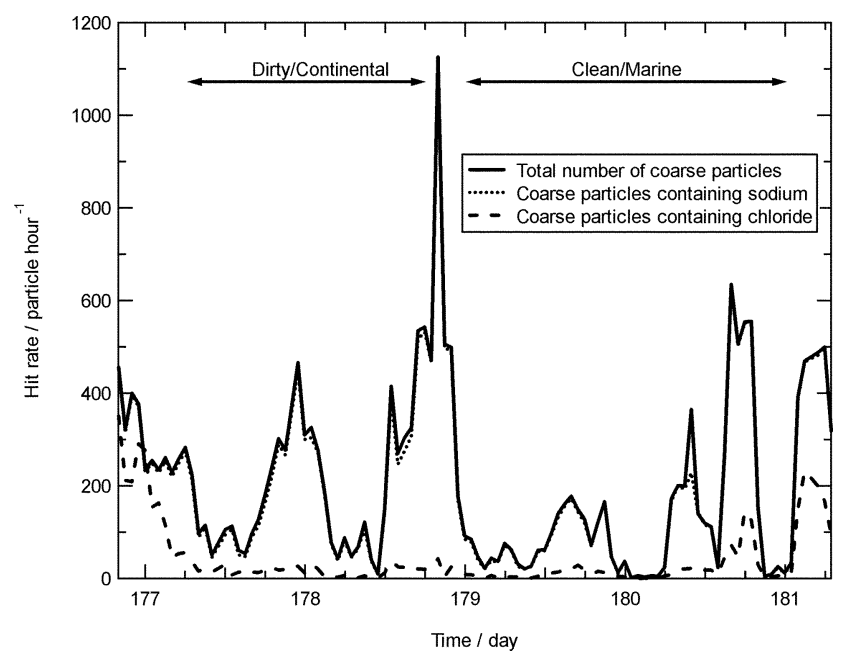

Fig. 3 The number of coarse particles detected per hour containing sodium or chloride. The figure demonstrates the depletion of particles containing chloride, especially the particles that have travelled overland, taken to indicate displacement reaction by nitrate. sodium closely tracked that of coarse particles containing sodium. Murphy and Thompson ${ }^{4}$ observed that even at Idaho Hill in Colorado, over $50 \%$ of particles contained sodium.

Potassium. Over $44 \%$ and $87 \%$ of fine and coarse particles, respectively, contained potassium (identified using $\mathrm{m} / \mathrm{z}=39$ AND $41 \mathrm{Da})$. The numbers of particles containing potassium and sodium were very strongly correlated. This can indicate a sea-salt origin, but potassium is also both a crustal component and a major trace element for plant growth. The widespread occurrence of potassium is therefore not surprising. An ATOFMS study of biomass burning in California noted that $>90 \%$ of particles contained potassium,${ }^{17}$ while another ATOFMS study detected potassium in California soil dust. ${ }^{14}$ Potassium has been reported as a biogenic component in the coarse fraction of particles collected in the Amazon. ${ }^{18}$ At Eskdalemuir the potassium signal was correlated with sodium and nitrate and, in the coarse component only, to the ions $\mathrm{CH}_{4} \mathrm{~N}^{+}$and $\mathrm{C}_{2} \mathrm{H}_{8} \mathrm{~N}^{+}$, which are indicative of amines. This latter association has not been previously reported.

Rubidium. The isotopes of $\mathrm{Rb}^{+}$at 85 AND $87 \mathrm{Da}$ are coincident with the organic ions $\mathrm{C}_{7} \mathrm{H}^{+}$and $\mathrm{C}_{7} \mathrm{H}_{3}{ }^{+}$Since these latter two ions should also occur with the $\mathrm{C}_{7} \mathrm{H}_{2}{ }^{+}$ion $(86 \mathrm{Da})$, particles containing rubidium were identified using $m / z=85$ AND 87 NOT 86 Da. However, this may still not unequivocally distinguish between rubidium and organic hydrocarbon. Rubidium characterised in this way was present in $3.0 \%$ and $1.9 \%$ of fine and coarse particles, respectively, and correlated with, amongst others, lithium and caesium, cations thought to derive from the amines, and, particularly for fine particles, anions containing sulfur. Previous literature data on particulate rubidium is scarce. Rubidium has been detected as a component of aerosols associated with biomass burning. ${ }^{18}$ The correlation between rubidium and lithium noted in this work could be indicative of a common, soilrelated source.

Caesium. The caesium cation has $m / z=133 \mathrm{Da}$. This value may also correspond to the organic ion $\mathrm{C}_{11} \mathrm{H}^{+}$, so if it is assumed that the $\mathrm{C}_{11}{ }^{+}$ion occurs concurrently with $\mathrm{C}_{11} \mathrm{H}^{+}$, caesium may be identified by $m / z=133$ NOT $132 \mathrm{Da}$. Particles containing caesium were $1.1 \%$ and $1.2 \%$ of all fine and coarse particles, respectively. The temporal trend of caesium in coarse particles was similar to the trend in total coarse particle number, suggesting marine origin. The trend in fine particulate 
Table 3 Observed correlations between the number of fine $(d<2.5 \mu \mathrm{m})$ particles per hour containing the specified pairs of ions. A filled square indicates $r^{2} \geqslant 0.5$

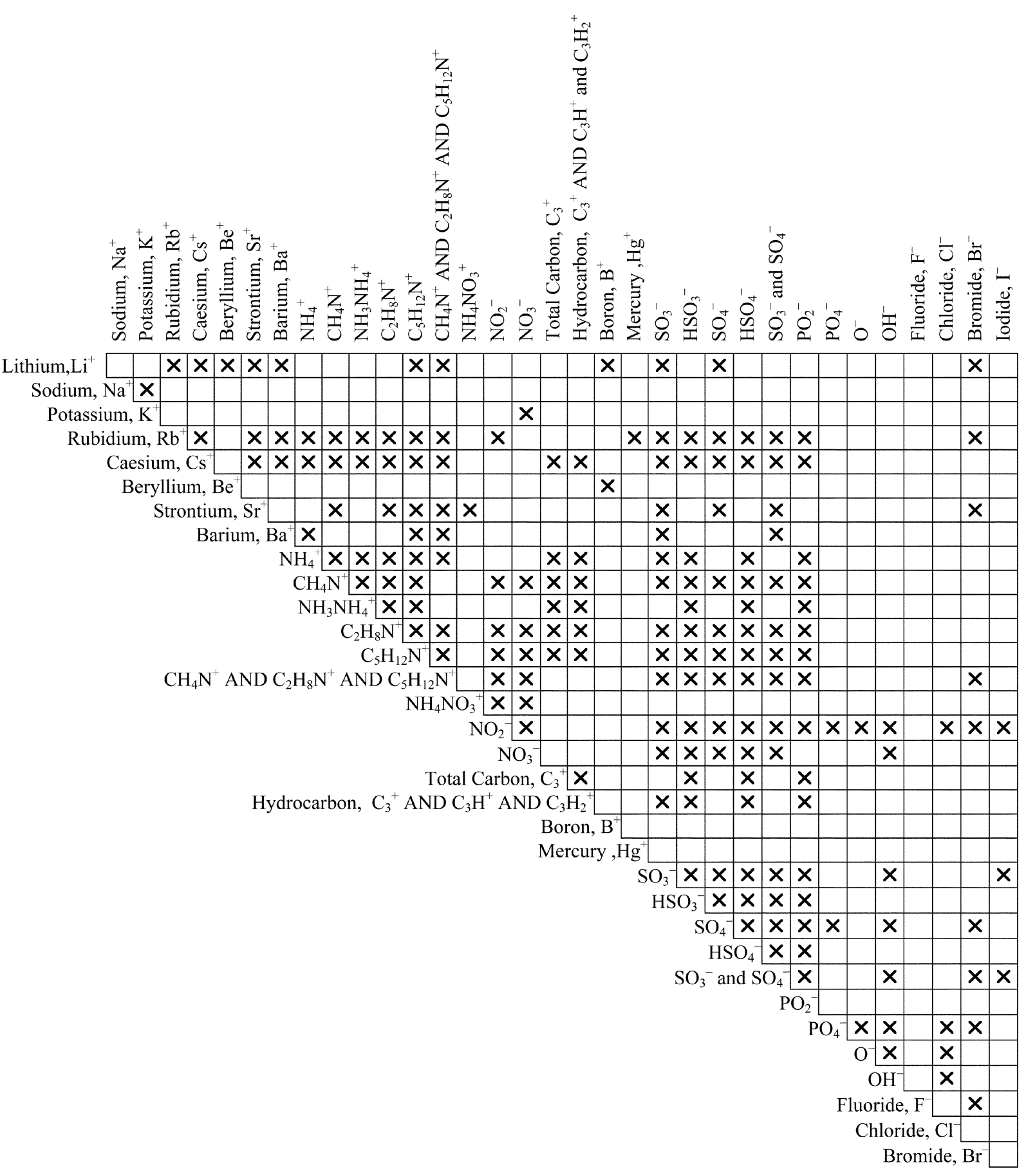

caesium signal correlated with fine organic carbon. As with rubidium, particles containing caesium correlated with lithium, amine-derived cations and anions containing sulfur.

Beryllium. Particles containing beryllium $(\mathrm{m} / \mathrm{z}=9 \mathrm{Da})$ were very infrequent $(<1 \%)$ and did not show any temporal trend. The only chemical species associated with beryllium in both fine and coarse particles were lithium and boron.

Magnesium and calcium. It was not possible reliably to distinguish peaks at $\mathrm{m} / \mathrm{z}=24,25$ and $26 \mathrm{Da}$ arising from isotopes of magnesium from those from the common molecular ions $\mathrm{C}_{2}{ }^{+}, \mathrm{C}_{2} \mathrm{H}^{+}$and $\mathrm{C}_{2} \mathrm{H}_{2}{ }^{+}$. Therefore no data for magnesium can be presented. Likewise, the $\mathrm{Ca}^{+}$ion $(m / z=40 \mathrm{Da})$ coincides with the $\mathrm{NaOH}^{+}$and $\mathrm{C}_{3} \mathrm{H}_{4}{ }^{+}$ions. Although, $\mathrm{C}_{3} \mathrm{H}_{4}{ }^{+}$ is not a common ion from hydrocarbons, the $\mathrm{NaOH}^{+}$ion is always observed in mass spectra of particles containing $\mathrm{Na}$. During this campaign nearly all coarse particles contained $\mathrm{Na}$ so attempts to determine calcium via $\mathrm{m} / \mathrm{z}=40 \mathrm{NOT} 36\left(\mathrm{C}_{3}{ }^{+}\right)$ NOT $23\left(\mathrm{Na}^{+}\right)$Da were unsuccessful.

Strontium. Strontium $(\mathrm{m} / \mathrm{z}=88 \mathrm{Da})$ was present in $2.4 \%$ and $3.8 \%$ of fine and coarse particles, respectively. Sea-salt particles play a role in the global distribution of strontium, and the strontium is often associated with calcium sulfate. ${ }^{19}$ In this study fine and coarse particles containing strontium did indeed correlate with particles yielding the sulfur containing ions $\mathrm{SO}_{3}{ }^{-}, \mathrm{SO}_{4}{ }^{-}, \mathrm{HSO}_{3}{ }^{-}$, and $\mathrm{HSO}_{4}{ }^{-}$, and strontium correlated with chloride in coarse particles. Artaxo and Hansson ${ }^{18}$ noted that strontium was associated with particles classed as biogenic 
Table 4 Observed correlations between the number of coarse $(d>2.5 \mu \mathrm{m})$ particles per hour containing the specified pairs of ions. A filled square indicates $r^{2} \geqslant 0.5$

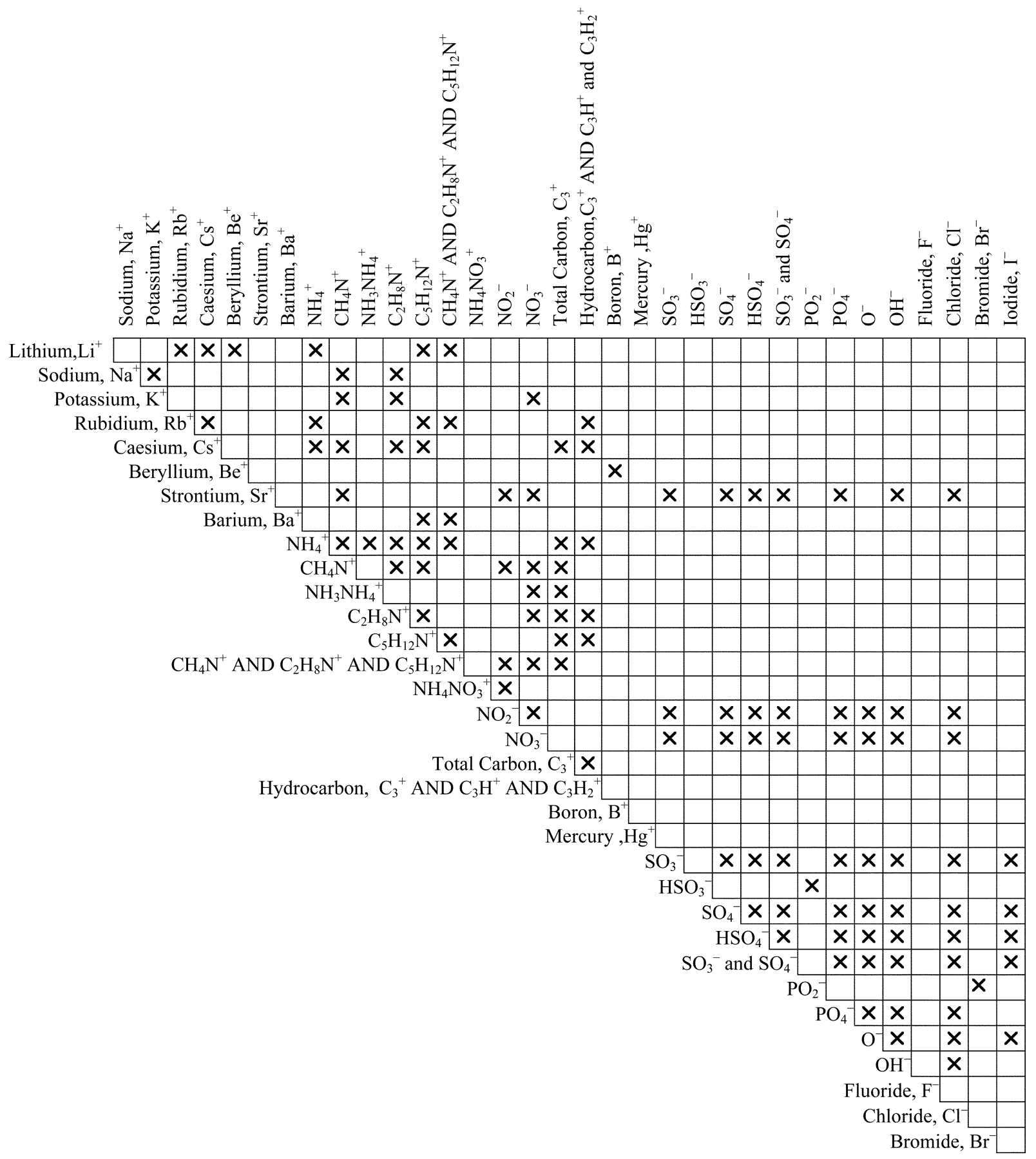

and containing the elements phosphorus and potassium. In this study, coarse strontium containing particles correlated with the $\mathrm{PO}_{4}{ }^{-}$ion, but not with potassium.

Barium. Coarse and fine particles containing barium $(\mathrm{m} / \mathrm{z}=$ $138 \mathrm{Da})$ were more prevalent when the site was impacted mainly by a dirty air mass. This is expected since the main source of barium in particles is crustal or vehicle emissions. Barium has been detected in Californian soil dust ${ }^{14}$ and particles from the automobile emissions of light and heavy duty vehicles. ${ }^{15}$ The latter was attributed mainly to vehicle, or more specifically, brake-wear.

Mercury. Particulate mercury was determined using $\mathrm{m} / \mathrm{z}=$ 200 AND $202 \mathrm{Da}$ and was detected in $0.4 \%$ and $0.2 \%$ of total fine and coarse particles, respectively. Although traditional filter sampling techniques have shown mercury containing particles at ground level, the occurrence of mercury in atmospheric particles detected at ground level was not reported by Murphy and Thomson ${ }^{4}$ who also used a single-particle mass-spectrometer. In general, particles containing $\mathrm{Hg}$ did not correlate with any other species studied.

Boron. Particles containing boron $(\mathrm{m} / \mathrm{z}=11 \mathrm{Da})$ were rare and distributed evenly between fine and coarse particles $(0.4 \%$ and $0.5 \%$, respectively). Correlations existed between boron, lithium and beryllium in fine particles and between boron and beryllium in coarse particles. The source of the boron or the correlation is not known. Fogg and Duce ${ }^{20}$ have suggested that sea-salt aerosol is a major source of atmospheric boron, however, the absence of a correlation between the occurrence of boron and sodium in coarse particles detected in this work 
does not support this. Murphy and Thomson ${ }^{4}$ detected boron in $5 \%$ of the particles they analysed by a single particle mass spectrometer at Idaho hill, Colorado. The authors report that the presence of boron was always accompanied by a signal for the $\mathrm{C}^{+}$ion but was negatively correlated to elemental carbon, and uncorrelated with the signals for potassium and iron. It was not known whether the origin of the $\mathrm{C}^{+}$peak was organic or inorganic carbon.

Carbon containing particles. When Eskdalemuir was impacted with polluted air masses, a large proportion of the particles contained carbon. Particles containing elemental or organic carbon yielded characteristic positive mass spectra with progressions of $\mathrm{C}_{n}{ }^{+}$and $\mathrm{C}_{n} \mathrm{H}_{m}{ }^{+}$ions, respectively. Values of $n$ and $m$ were typically $1-10$ and $1-3$, respectively. Similar, but weaker, progressions of ions were observed in the negative ion mode. The following combinations were tried as markers for total carbon: $\mathrm{C}^{+}$only, $\mathrm{C}_{3}{ }^{+}$only, $\mathrm{C}^{+} \mathrm{AND} \mathrm{C}_{3}{ }^{+} \mathrm{AND} \mathrm{C}_{7}{ }^{+}$. The marker $\mathrm{C}_{3}{ }^{+}$proved most useful. The combinations: $\mathrm{C}^{+}$AND $\mathrm{CH}^{+}$AND $\mathrm{CH}_{2}{ }^{+}$, and $\mathrm{C}_{3}^{+}$AND $\mathrm{C}_{3} \mathrm{H}^{+}$AND $\mathrm{C}_{3} \mathrm{H}_{2}{ }^{+}$were tried as markers for organic carbon, the $\mathrm{C}_{3}{ }^{+}$AND $\mathrm{C}_{3} \mathrm{H}^{+}$AND $\mathrm{C}_{3} \mathrm{H}_{2}{ }^{+}$series was found to be the most useful.

Fig. 4 shows the temporal variation of fine particles containing total carbon (defined using $\mathrm{m} / \mathrm{z}=\mathrm{C}_{3}{ }^{+}$) and hydrocarbon (defined using $m / z=\mathrm{C}_{3}{ }^{+}$AND $\mathrm{C}_{3} \mathrm{H}^{+}$AND $\mathrm{C}_{3} \mathrm{H}_{2}{ }^{+}$). It is clear that when Eskdalemuir was subjected to a dirty continental air mass, characterised by a large increase in numbers of fine particles, the majority of the fine particles contained carbon. Noteworthy from Fig. 4 is the almost constant factor between the number of particles yielding $\mathrm{C}_{3}{ }^{+}$ and $\left(\mathrm{C}_{3}{ }^{+}\right.$AND $\mathrm{C}_{3} \mathrm{H}^{+}$AND $\left.\mathrm{C}_{3} \mathrm{H}_{2}{ }^{+}\right)$, reflected in the large correlation coefficients of $r^{2}=0.98$ (Fig. 5) and $r^{2}=0.82$ in fine and coarse particles, respectively. The difference in the number of particles containing $\mathrm{C}_{3}{ }^{+}$and $\left(\mathrm{C}_{3}{ }^{+}\right.$AND $\mathrm{C}_{3} \mathrm{H}^{+}$ AND $\left.\mathrm{C}_{3} \mathrm{H}_{2}^{+}\right)$is an indicator of the number of particles containing elemental carbon. The slope of Fig. 5 indicates that, on average, $37 \pm 3 \%$ of carbon containing fine particles were organic carbon during the sampling period at Eskdalemuir. For coarse particles the proportion was $52 \pm 8 \%$ (data not shown). Errors are $95 \%$ confidence intervals. These proportions correspond to EC/OC number ratios of 1.7 and 0.9 for fine and coarse particles, respectively. For comparison, Finlayson-Pitts and Pitts $^{21}$ quote EC/OC ratios of around unity, while Castro et l. $^{22}$ report EC/OC ratios for particles collected on quartz-fibre filters for urban and rural sites in the UK, Ireland and Portugal. Their maximum EC/OC value of 0.9 corresponded to conditions of low photochemical activity.



Fig. 4 The number of fine particles detected per hour containing total carbon $\left(\mathrm{C}_{3}{ }^{+}\right)$and organic carbon $\left(\mathrm{C}_{3}{ }^{+}\right.$and $\mathrm{C}_{3} \mathrm{H}^{+}$and $\left.\mathrm{C}_{3} \mathrm{H}_{2}{ }^{+}\right)$. The majority of fine particles during the dirty episode contained carbon.

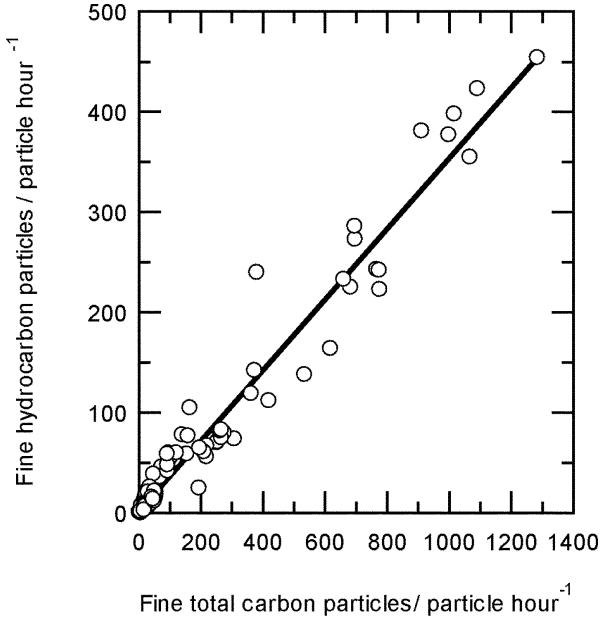

Fig. 5 A scatter plot of number of fine particles per hour containing total carbon $\left(\mathrm{C}_{3}{ }^{+}\right)$and organic carbon $\left(\mathrm{C}_{3}{ }^{+}\right.$AND $\mathrm{C}_{3} \mathrm{H}^{+}$AND $\left.\mathrm{C}_{3} \mathrm{H}_{2}{ }^{+}\right) \cdot r^{2}=0.98$

EC/OC ratios of 1.0 and 1.35 have been reported for the Los Angeles basin ${ }^{23}$ and an urban area in Japan, ${ }^{24}$ respectively. The value of EC/OC is generally lower during photochemical activity, and after long-range transport, due to increased gas to particle conversion from the oxidation of volatile organic compounds. The higher EC/OC ratio at Eskdalemuir for fine particles indicates atmospheric conditions not conducive to secondary organic aerosol formation. However the EC/OC ratios reported by the ATOFMS are number ratios, i.e. $\frac{n(\mathrm{EC})}{n(\mathrm{OC})}$, where $n(\mathrm{EC})$ and $n(\mathrm{OC})$ are the number of particles in an hourly period containing just elemental carbon or hydrocarbon respectively. Literature values of $\mathrm{EC} / \mathrm{OC}$ ratios are often reported as a mass ratio recorded over periods from $24 \mathrm{~h}$ to 7 days, i.e. $\frac{m(\mathrm{EC})}{m(\mathrm{OC})}$ where $m(\mathrm{EC})$ and $m(\mathrm{OC})$ are the mass of elemental and organic carbon respectively. The ATOFMS data are, at present, subject to a size sampling bias. Nevertheless, the above analysis demonstrates the usefulness of the singleparticle technique in distinguishing changes in EC/OC ratios with particle size in real time. The interesting question of the response of the ATOFMS to particles containing both organic and elemental carbon particles, say formed from the condensation of organic particles onto an elemental carbon core, would make an interesting future study.

The fine and coarse particles containing carbon correlated with nearly all the ammonium and amine species measured as well as the sulfur containing anions. A time-series plot for fine particles is shown in Fig. 6.

Ammonium nitrate. The proportions of fine and coarse particles containing $\mathrm{NH}_{4} \mathrm{NO}_{3}(\mathrm{~m} / z=80 \mathrm{Da})$ were $3.5 \%$ and $9.3 \%$, respectively. The number of fine particles yielding $\mathrm{NH}_{4} \mathrm{NO}_{3}{ }^{+}$increased during the period when air masses had passed over the UK. Tables 3 and 4 show that particles yielding $\mathrm{NH}_{4} \mathrm{NO}_{3}{ }^{+}$correlated with few other chemical components.

Ammonium. Ammonium ion was defined by $m / z=18 \mathrm{Da}$. Although this may also correspond to $\mathrm{H}_{2} \mathrm{O}^{+}$, mass spectra obtained by Thomson and Murphy ${ }^{4}$ for wet salt particles generated in laboratory studies yielded little or no ions at $18 \mathrm{Da}$, so it is assumed that $18 \mathrm{Da}$ observed in the field is primarily due to $\mathrm{NH}_{4}{ }^{+}$. This is corroborated by the strong correlation between the presence of $\mathrm{m} / \mathrm{z}=18$ and $\mathrm{m} / \mathrm{z}$ values corresponding to $\mathrm{NH}_{3} \mathrm{NH}_{4}^{+}, \mathrm{CH}_{4} \mathrm{~N}^{+}$, and $\mathrm{C}_{5} \mathrm{H}_{12} \mathrm{~N}^{+}$(Tables 3 and 4). Both Hughes et al. ${ }^{25}$ and Whiteaker et al. ${ }^{26}$ detected $\mathrm{NH}_{4}{ }^{+}$in particles using ATOFMS instruments and found that the species was more prevalent in air that had passed over sources of ammonia in the Los Angles Basin and had stagnated. Carson et al. ${ }^{27}$ showed that $\mathrm{NH}_{4}{ }^{+}$is readily detected by mass 


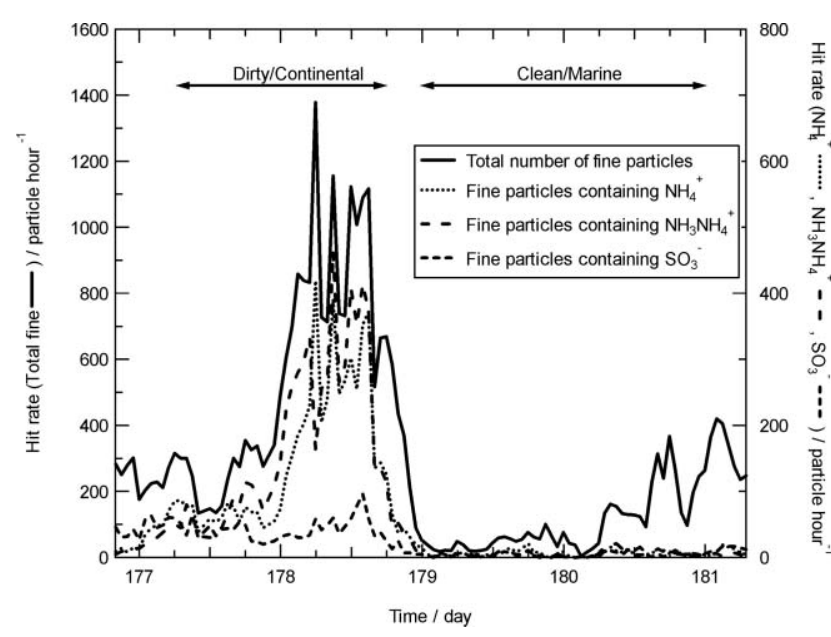

Fig. 6 The number of hourly occurrences of $\mathrm{NH}_{4}{ }^{+}, \mathrm{NH}_{3} \mathrm{NH}_{4}{ }^{+}$and $\mathrm{SO}_{3}{ }^{-}$ions in fine particles relative to hourly occurrence of total fine particles.

spectrometry when ammonium nitrate, deposited on the surface of particulate matter, is subject to laser-ablation. Fig. 6 demonstrates that the air mass which impacted on Eskdalemuir on day 178 and had travelled over the UK had acquired considerable ammonium on its journey en route. The source of ammonia could be agricultural and/or road traffic.

Amines. The $\mathrm{m} / \mathrm{z}$ values of 58 and $86 \mathrm{Da}$ were assigned to $\mathrm{C}_{3} \mathrm{H}_{8} \mathrm{~N}^{+}$and $\mathrm{C}_{5} \mathrm{H}_{12} \mathrm{~N}^{+}$ions, respectively. The occurrence of $\mathrm{m} / \mathrm{z}=30 \mathrm{Da}$ was also considered, although this may be due to $\mathrm{CH}_{4} \mathrm{~N}^{+}$or to $\mathrm{NO}^{+}$ions, so the criterion $\mathrm{m} / z=30$ AND 58 AND 86 Da was taken to represent a signal for amines in general. The temporal profile of particles containing $\mathrm{CH}_{4} \mathrm{~N}^{+}$ (or $\mathrm{NO}^{+}$), $\mathrm{C}_{3} \mathrm{H}_{8} \mathrm{~N}^{+}, \mathrm{C}_{5} \mathrm{H}_{12} \mathrm{~N}^{+}$was similar. Particles containing these ions would be expected to also give a signal for organic carbon and so the strong correlation of the amine signal with the organic carbon signal is expected.

Following their campaign at Idaho Hill, Murphy and Thomson ${ }^{4}$ noted that the amine signals, reported as peaks in the positive ion mass spectrum at $18,30,58$ and $88 \mathrm{Da}$, correlated with a wind direction that passed "over vegetated terrain from Denver urban areas and the large feedlots in eastern Colorado." Studies by Angelino et al. ${ }^{28}$ and Silva and Prather $^{29}$ demonstrated that peaks at $86 \mathrm{Da}$ arise from secondary and tertiary amines. The work by Angelino et l. $^{28}$ also demonstrated that strong amine signals arise from automotive exhausts from a busy freeway. Measurements of amines in the atmosphere have also been reported from agricultural $^{30}$ and marine ${ }^{31}$ sources. ${ }^{32}$ The data presented here are consistent with background coarse aerosol containing amines from a marine and/or agricultural origin.

3.3.2 Negative ions. Fluorine. Only $0.3 \%$ of particles contained fluorine (identified by $m / z=-19$ ). This is broadly in agreement with Murphy et $a l^{33}$ who report that only $1 \%$ of particles contained fluorine at a coastal site (Cape Grim, Tasmania). No data on the occurrence of fluorine are reported by Murphy and Thompson ${ }^{34}$ in their inland study at Idaho Hill, Colorado. The fluoride at Eskdalemuir did not correlate with any other chemical component studied, making it difficult to suggest a source, although it is probably marine. Murphy et al. ${ }^{33}$ report that fluoride in particles at Cape Grim was correlated with $\mathrm{O}^{-}$and $\mathrm{OH}^{-}$ions but this was not observed here. Sources of fluorine in particulate matter have also been reported as coal burning, ${ }^{35,36}$ brazing and welding, ${ }^{37}$ and volcanoes. ${ }^{38}$ The source at Eskdalemuir is not known.
Chlorine. Chlorine was determined using $\mathrm{m} / \mathrm{z}=-35 \mathrm{Da}$, but NOT $m / z=-37$ Da because of ambiguity of the latter with $\mathrm{C}_{3} \mathrm{H}^{-}$. Chloride was present in $6.1 \%$ and $20.4 \%$ of fine and coarse particles analysed.

Murphy and Thomson ${ }^{34}$ observed chloride in approximately $20 \%$ of all particles detected at Idaho hill, Colorado, in broad agreement with the Eskdalemuir data. An anti-correlation of chloride with nitrate is evidence of the reaction of $\mathrm{HNO}_{3}$ with $\mathrm{NaCl},{ }^{39}$

$$
\mathrm{HNO}_{3}+\mathrm{NaCl} \rightarrow \mathrm{NaNO}_{3}+\mathrm{HCl}
$$

In this dataset, $\mathrm{Cl}^{-}$in coarse particles correlated positively with $\mathrm{NO}_{3}{ }^{-}$(and with $\mathrm{SO}_{4}{ }^{-}$). However, Fig. 7 shows a plot of the ratio of the numbers of coarse particles containing $\mathrm{NO}_{3}{ }^{-}$ and $\mathrm{Cl}^{-}$with time, and indicates that, for the particles detected during the period when Eskdalemuir was impacted by dirty air, the chloride originally present in the particles had been exchanged, presumably by reaction (1), for nitrate. This is in agreement with studies using filters ${ }^{40}$ and a single particle mass spectrometer. $^{41}$

Bromine. The temporal trends of fine and coarse particles containing bromine (defined by $m / z=-79$ AND $-81 \mathrm{Da}$ ) were similar, peaking in the mornings of day 177 and 181, and the evenings of days 178 and 179. Bromine was not detected at Idaho Hill, Colorado, ${ }^{34}$ but was detected at a coastal site at Cape Grim, Tasmania. ${ }^{33}$ Murphy et al. ${ }^{33}$ suggested that bromide was not detected at Idaho Hill because it had been displaced from the particles by sulfate ions. These workers showed that, for particles at Cape Grim, a decrease in bromine signal corresponded to an increase in sulfate signal. Plotting the ratio of $\mathrm{NO}_{3}{ }^{-}$to $\mathrm{Br}^{-}$and $\mathrm{SO}_{4}{ }^{-}$to $\mathrm{Br}^{-}$versus time for the data here does suggest a high ratio of nitrate to bromide during the dirty air period and a low ratio of nitrate to bromide during the clean air periods, although the ratio of $\mathrm{SO}_{4}{ }^{-}$to $\mathrm{Br}^{-}$does not demonstrate any trend. Reactions between nitrogen oxides and acids with $\mathrm{NaBr}$ and $\mathrm{Br}^{-}$in sea water particles have been studied in the laboratory and are suggested to occur in the atmosphere. $^{21}$

Iodine. Iodine $(\mathrm{m} / \mathrm{z}=-127)$ was detected in only $0.7 \%$ and $1.2 \%$, respectively, of fine and coarse particles analysed. Previous single particle studies of costal marine air have suggested that, in the presence of low sulfate, the amount of iodide in marine particles correlated with the organic content. $^{33,42}$ Anti-correlations between sulfate and iodide,

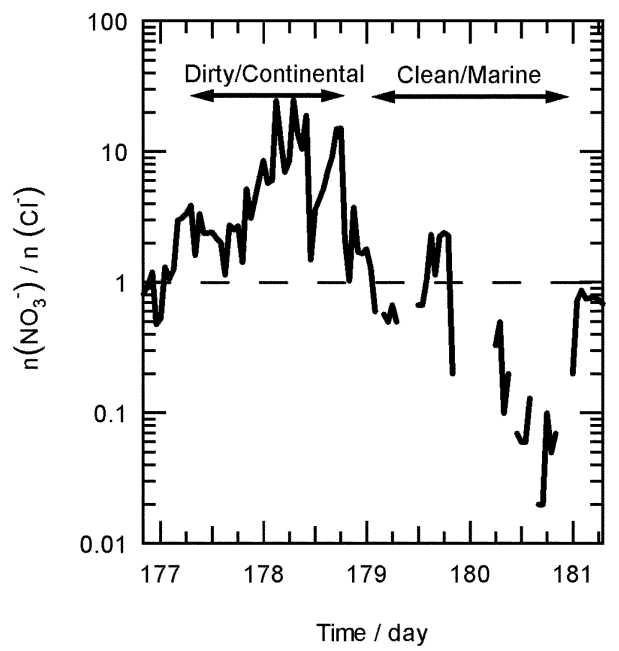

Fig. 7 The temporal trend in the ratio $\frac{n\left(\mathrm{NO}_{3}^{-}\right)}{n\left(\mathrm{Cl}^{-}\right)}$of the number of coarse particles per hour containing nitrate and chloride. The ratio is greater than unity during the dirty period and less than unity during the clean period. 
bromide and chloride have also been observed. ${ }^{31}$ From an analysis of 5 years of aerosol data collected at Mace head, Ireland, Huang et $a l .{ }^{43}$ have suggested an additional source of iodine in particulate matter other than sea salt, while O'Dowd et al. ${ }^{44}$ demonstrated that particle formation was possible from volatile organoiodine compounds of marine origin. In this work, the ratio of the number of coarse particles containing iodine to the number containing $\mathrm{NO}_{3}{ }^{-}$was unchanged throughout the campaign and the occurrence of iodine correlated with the occurrence of sulfate.

Nitrate (and nitrite). The $\mathrm{NO}_{2}{ }^{-}$ion $(m / z=-46 \mathrm{Da})$ strongly correlates with the $\mathrm{NO}_{3}{ }^{-}(\mathrm{m} / z=-62 \mathrm{Da})$, although the ratio of number of particles with signals at -62 to -46 was not unity (Table 5) because of interference at $m / z=-62 \mathrm{Da}$ from the $\mathrm{C}_{5} \mathrm{H}_{2}{ }^{-}$ion. Using the criterion $\mathrm{m} / z=-62$ NOT -60 considerably improved the -62 to -46 ratio (Table 5). In laboratory trials, nebulised solutions containing $\mathrm{NO}_{3}{ }^{-}$ions always yielded a strong signal at -46 as well as $-62 \mathrm{Da}$. It is proposed that $\mathrm{NO}_{2}{ }^{-}$may be formed in the ablation process from $\mathrm{NO}_{3}{ }^{-}$anion in the aerosol and is indicative of $\mathrm{NO}_{3}{ }^{-}$. During the campaign a signal for nitrite was not observed without a signal for $\mathrm{NO}_{3}{ }^{-}$. Thus the signal at $-46 \mathrm{Da}$ appears to be a good marker for $\mathrm{NO}_{3}{ }^{-}$

Particles containing nitrate correlated strongly with particles containing sulfate.

Sulfur containing anions. The following sulfur containing anions were monitored: $\mathrm{SO}_{3}{ }^{-}(\mathrm{m} / \mathrm{z}=-80 \mathrm{Da}), \mathrm{HSO}_{3}{ }^{-}(\mathrm{m} / \mathrm{z}=$ $-81 \mathrm{Da}), \mathrm{SO}_{4}{ }^{-}(\mathrm{m} / \mathrm{z}=-96 \mathrm{Da})$ and $\mathrm{HSO}_{4}{ }^{-}(\mathrm{m} / z=-97 \mathrm{Da})$. The signal at $m / z=-80 \mathrm{Da}$ is almost certainly $\mathrm{SO}_{3}{ }^{-}$, but signals at $-81,-96$ and $-97 \mathrm{Da}$ may be $\mathrm{Br}^{-}, \mathrm{C}_{8}{ }^{-}$and $\mathrm{C}_{8} \mathrm{H}^{-}$, respectively. Thus $\mathrm{HSO}_{3}{ }^{-}$was characterised in two ways, using $-81 \mathrm{Da}$ alone or $-81 \mathrm{NOT}-79 \mathrm{Da}$. The anion $\mathrm{C}_{8}{ }^{-}(-96 \mathrm{Da})$ was not usually observed without $\mathrm{C}_{7}^{-}(-84 \mathrm{Da})$, so the presence of $\mathrm{SO}_{4}{ }^{-}$was inferred by comparing signals at $-96 \mathrm{Da}$ and -96 NOT $-84 \mathrm{Da}$. However, the occurrence of the $\mathrm{C}_{8}{ }^{-}$ ion was rare, so the difference between the two methods was negligible. Since the occurrence of the $\mathrm{C}_{8} \mathrm{H}^{-}$ion was likewise very rare, the signal at $-97 \mathrm{Da}$ was taken to indicate the presence of $\mathrm{HSO}_{4}^{-}$.

$\mathrm{SO}_{3}{ }^{-}$and $\mathrm{HSO}_{3}{ }^{-}$. Fine particles containing $\mathrm{SO}_{3}{ }^{-}$and $\mathrm{HSO}_{3}{ }^{-}$were more prevalent during the first half of the measurement period. The number of particles giving a signal for $\mathrm{SO}_{3}{ }^{-}$and $\mathrm{HSO}_{3}{ }^{-}$increased markedly during the pollution event on day 178 (Fig. 6), and was not correlated with the signal from fine particles containing organic species.

$\mathrm{SO}_{4}{ }^{-}$and $\mathrm{HSO}_{4}{ }^{-}$. Fine particles containing $\mathrm{SO}_{4}{ }^{-}$were more numerous during the first half of the campaign and peaked during the polluted air mass on day 178. The number of fine particles containing $\mathrm{HSO}_{4}{ }^{-}$increased significantly during the polluted air mass influence, increasing from below $50 \mathrm{~h}^{-1}$ to over $200 \mathrm{~h}^{-1}$ during this period. In contrast, coarse particles containing $\mathrm{SO}_{4}{ }^{-}$and $\mathrm{HSO}_{4}{ }^{-}$peaked during the first few hours of the campaign and decreased throughout the remaining time.

Table 5 The ratio of the number of occurrences of $m / z=-62$ Da or $\mathrm{m} / z=-62 \mathrm{NOT}-60$ to $\mathrm{m} / z=-46 \mathrm{Da}$, for fine and coarse particles. A signal at $m / z=-46$ is assumed to indicate $\mathrm{NO}_{2}{ }^{-}$. A peak at $\mathrm{m} / \mathrm{z}=$ -62 may indicate $\mathrm{NO}_{3}{ }^{-}$or $\mathrm{C}_{5} \mathrm{H}_{2}{ }^{-}$. The latter can be accounted for using $m / z=-60\left(\mathrm{C}_{5}^{-}\right)$

\begin{tabular}{lll}
\hline $\begin{array}{l}m / z \text { query used to detect } \\
\text { presence of } \mathrm{NO}_{3}{ }^{-}\end{array}$ & Fine & Coarse \\
\hline-62 & $0.78 \pm 0.04$ & $0.91 \pm 0.07$ \\
-62 NOT -60 & $0.90 \pm 0.06$ & $1.00 \pm 0.06$ \\
\hline
\end{tabular}

Phosphorus containing anions: $\mathrm{PO}_{2}^{-}$and $\mathrm{PO}_{4}{ }^{-}$. The phosphorus containing anions $\mathrm{PO}_{2}^{-}$and $\mathrm{PO}_{4}^{-}$were monitored using $m / z=-63$ and $-95 \mathrm{Da}$, respectively. The latter is believed to be free from interference but $\mathrm{PO}_{2}{ }^{-}$may have interference from $\mathrm{C}_{5} \mathrm{H}_{3}{ }^{-}$. However, carbonaceous particles did not usually yield extensive negative ion mass spectra so the $\mathrm{C}_{5}{ }^{-}$ ion was considerably less common then the $\mathrm{C}_{5}{ }^{+}$ion and monitoring particles containing $\mathrm{PO}_{2}{ }^{-}$using $-63 \mathrm{Da}$ alone, or -63 NOT -60 Da gave very similar results. Attempts to monitor the $\mathrm{PO}_{3}{ }^{-}$anion at $\mathrm{m} / \mathrm{z}=-79 \mathrm{Da}$ were unsuccessful due to interferences from $\mathrm{Br}^{-}$.

Phosphates have been detected in Californian soil dust, ${ }^{14}$ and have also been attributed to industrial sources. ${ }^{45,46}$ However, Artaxo and Hansson ${ }^{18}$ apportioned phosphorus to a biogenic source in a forested area. Particulate lipid phosphorus is found in coastal waters ${ }^{47}$ and could be transferred to the atmosphere by wave motion and bubble bursting. In this study, fine and coarse particles giving rise to $\mathrm{PO}_{4}{ }^{-}$ions had different temporal patterns to those giving rise to $\mathrm{PO}_{2}{ }^{-}$ions. The trends in the occurrence of $\mathrm{PO}_{2}{ }^{-}$and $\mathrm{PO}_{4}{ }^{-}$seem to indicate that either the two species have different sources or that one of the signals is better representing a separate, unidentified species.

$\mathrm{O}^{-}$and $\mathrm{OH}^{-}$. Peaks at $\mathrm{m} / \mathrm{z}=-16$ and -17 Da were assigned to $\mathrm{O}^{-}$and $\mathrm{OH}^{-}$ions respectively. The peaks commonly (but not always) appeared in conjunction with oxy-anions such as sulfate. Fine and coarse particles giving rise to $\mathrm{O}^{-}$and $\mathrm{OH}^{-}$ions tended to peak in number at the same times.

\section{Conclusions}

The deployment of the aerosol time of flight mass spectrometer at the remote inland site of Eskdalemuir, southern Scotland, has yielded unprecedented time-resolution of the chemical composition of the UK remote background aerosol under two distinct air mass regimes: marine, and air masses that had passed slowly over the UK. The number of fine particles was very considerably elevated during the latter air mass type. Allowing for any sensitivity bias, one in three of all fine particles containing carbon consisted of organic carbon (hydrocarbon). The proportion for coarse particles containing carbon was one in two.

Analysis of these single-particle data shows that an air mass with marine origin that passes slowly over UK agricultural land accumulated amines and ammonium, when compared with air masses that had not. In addition, the ratio between the numbers of coarse particles containing nitrate or chloride anions was shown to be greater than unity for an air mass that travelled over the UK and less than unity for direct marine air masses, providing evidence for chloride displacement from sea-salt particles by acidic gases. Similar ratios for bromide and iodide to nitrate suggested similar but less conclusive behaviour to chloride.

The ATOFMS has particular advantage in detecting the lighter elements lithium, beryllium and boron which are not usually detected by conventional analytical methods in filter pack sampling. Although rare, these elements, when detected using the ATOFMS in these UK air masses, were generally correlated, perhaps suggesting an unusual source not previously recognised.

\section{Acknowledgements}

The EPSRC provided financial support for this project. We are grateful to J. Riddick, E. Scott and D. Kerridge of the British Geological Survey for access and assistance at the Eskdalemuir site. We also acknowledge use of the British Atmospheric Data 
Centre (BADC) and the data supplied to it by the European Centre for Medium range Weather Forecasts (ECMWF).

\section{References}

1 Airborne Particles Expert Group (APEG), Source apportionment of particulate matter in the United Kingdom, DETR, HMSO, London, 1999.

2 C. A Noble and K. A. Prather, Environ. Sci. Technol., 1996, 30, 2667.

3 C. A. Noble and K. A. Prather, Geophys. Res. Lett., 1997, 24, 2753.

4 D. M. Murphy and D. S. Thomson, J. Geophys. Res., 1997, 102, 6341

5 A. Trimborn, K. P. Hinz and B. Spengler, Aerosol Sci. Tech., 2000, 33, 191.

6 J. T. Jayne, D. C. Leard, X. F. Zhang, P. Davidovits, K. A. Smith, C. E. Kolb and D. R. Worsnop, Aerosol Sci. Tech., 2000, 33, 49.

7 R. V. Mallina, A. S. Wexler, K. P. Rhoads and M. V. Johnston, Aerosol Sci. Tech., 2000, 33, 87.

8 M. J. Coggiola, Z. Shi and S. E. Young, Aerosol Sci. Tech., 2000, 33, 20.

9 W. D. Reents and M. J. Schabel, Anal. Chem., 2001, 73, 5403.

10 J. O. Allen, D. P. Fergenson, E. E. Gard, L. S. Hughes, B. D. Morrical, M. J. Kleeman, D. S. Gross, M. E. Galli, K. A. Prather and G. R. Cass, Environ. Sci. Technol., 2000, 34, 211.

11 K. R. Neubauer, M. V. Johnston and A. S. Wexler, Int. J. Mass Spectrom., 1995, 151, 77; K. R. Neubauer, M. V. Johnston and A. S. Wexler, Atmos. Environ., 1998, 32, 2521; D. S. Thomson and D. M. Murphy, Appl. Optics, 1993, 32, 6818; P. G. Carson, M. V. Johnston and A. S. Wexler, Rapid. Commum. Mass. Spectrom., 11, 993; A. C. Lazar, P. T. A. Reilly, W. B. Whitten and J. M. Ramsey, Anal. Chem., 2000, 72, 2142; B. A. Mansoori, M. V. Johnston and A. S. Wexler, Anal. Chem., 1994, 66, 3681; B. A. Mansoori, M. V. Johnston and A. S. Wexler, Anal. Chem., 1996, 68, 3595.

12 P. V. Bhave, M. J. Kleeman, J. O. Allen and L. S. Hughes, Environ. Sci. Technol., 2002, 36, 2154.

13 D. S. Gross, M. E. Galli, P. J. Silva and K. A. Prather, Anal. Chem., 2000, 72, 416

14 P. J. Silva, R. A. Carlin and K. A. Prather, Atmos. Environ., 2000, 34, 1811.

15 D. S. Gross, M. E. Galli, P. J. Silva, S. H. Wood, D. Y. Liu and K. A. Prather, Aerosol Sci. Tech., 2000, 32, 152; R. M. Harrison, R. Tilling, M. S. Callén Romero, S. Harrad and K. Jarvis, Atmos. Environ., 2003, 37, 2391.

16 N. N. Greenwood and A. Earnshaw, Chemistry of the Elements, Pergamon Press, Oxford, 1989.

17 P. J. Silva, D. Y. Liu, C. A. Noble and K. A. Prather, Environ. Sci. Technol., 1999, 33, 3068.

18 P. Artaxo and H. C. Hansson, Atmos. Environ., 1995, 29, 393.

19 C. E. Whipkey, R. C. Capo, O. A. Chadwick and B. W. Stewart, Chem. Geol., 2000, 168, 37.
20 T. R. Fogg and R. A. Duce, J. Geophys. Res., 1985, 90, 3781.

21 B. J. Finlayson-Pitts and J.N. Jr. Pitts, Chemistry of the upper and lower atmosphere: theory, experiments and applications, Academic Press, 2000.

22 L. M. Castro, C. A. Pio, R. M. Harrison and D. J. T. Smith, Atmos. Environ., 1999, 33, 2771.

23 B. J. Turpin and J. J. Huntzicker, Atmos. Environ., 1995, 29, 3527.

24 S. Kadowaki, Environ. Sci. Technol., 1990, 24, 741.

25 L. S. Hughes, J. O. Allen, P. Bhave, M. J. Kleeman, G. R. Cass, D. Y. Liu, D. F. Fergenson, B. D. Morrical and K. A. Prather, Environ. Sci. Technol., 2000, 34, 3058.

26 J. R. Whiteaker, D. T. Suess and K. A. Prather, Environ. Sci. Technol., 2002, 36, 2345.

27 P. G. Carson, M. V. Johnston and A. S. Wexler, Aerosol Sci. Tech., 1997, 26, 291.

28 S. Angelino, D. T. Suess and K. A. Prather, Environ. Sci. Technol., 2001, 35, 3130

29 P. J. Silva and K. A. Prather, Anal. Chem., 2000, 72, 3553.

30 G. W. Schade and P. J. Crutzen, J. Atmos. Chem., 1995, 22, 319.

31 A. van Neste, R. A. Duce and C. Lee, Geophys. Res. Lett., 1987, 14, 711 .

32 K. Gorzelska and J. N. Galloway, Global Biogeochemical Cycles., 1990, 4, 309.

33 D. M. Murphy, D. S Thomson and A. M. Middlebrook, Geophys. Res. Lett., 1997, 24, 3197.

34 D. M. Murphy and D. S. Thomson, J. Geophys. Res., 1997, 102, 6353.

35 M. Ando, M. Tadano, S. Yamamoto, K. Tamura, S. Asanuma, T. Watanabe, T. Kondo, S. Sakurai, R. D. Ji, C. Liang, X. Q. Chen, Z. Hong and S. Cao, Sci. Total Environ., 2001, 271, 107.

36 Y. Zhang and S. R. Cao, Fluoride, 1996, 29, 207.

37 A. T. Zimmer and P. Biswas, Am. Ind. Hyg. Assoc. J., 2000, 61, 351.

38 A. G. Allen, P. J. Baxter and C. J. Ottley, Bull. Volcanol., 2000, 62,

39 R. Vogt, P. J. Crutzen and R. Sander, Nature, 1996, 383, 327.

40 L. M. McInnes, D. S. Covert, P. K. Quinn and M. S. Germani, J. Geophys. Res., 1994, 99, 8257.

41 E. E. Gard, M. J. Kleeman, D. S. Gross, L. S. Hughes, J. O. Allen, B. D. Morrical, D. P. Fergenson, T. Dienes, M. E. Galli, R. J. Johnson, G. R. Cass and K. A. Prather, Science, 1998, 279, 1184.

42 A. M. Middlebrook, D. M. Murphy and D. S. Thomson, J. Geophys. Res., 1998, 103, 16475.

43 S. Huang, R. Arimoto and K. A. Rahn, Atmos. Environ., 2001, 35, 1421.

44 C. D. O’Dowd, J. L. Jimenez, R. Bahreini, R. C. Flagan, J. H. Seinfeld, K. Hameri, L. Pirjola, M. Kulmala, S. G. Jennings and T. Hoffmann, Nature, 2002, 417, 632.

45 C. Migon, V. Sandroni and J. P. Bethoux, Mar. Environ. Res., 2001, 52, 413.

46 E. Ganor, Z. Levin and R. Van Grieken, Atmos. Environ., 1998, 32, 1631 .

47 M. Suzumura and E. D. Ingall, Mar. Chem., 2001, 75, 141. 